\begin{tabular}{|l|l|l|}
\hline \multirow{2}{*}{$\begin{array}{l}\text { INTERNATIONAL } \\
\text { ENGINEERING, } \\
\text { SCIENCE AND } \\
\text { EDUCATION } \\
\text { GROUP }\end{array}$} & $\begin{array}{l}\text { International Journal of Health Services Research and Policy } \\
(2019) \text { 4(1):43-54 } \\
\text { INESEG } \\
\text { doi: } 10.23884 \text { /ijhsrp.2019.4.1.05 } \\
\text { e-ISSN: 2602-3482 } \\
\text { Received: February 21, 2019 } \\
\text { Submission Type: Research Article }\end{array} \quad$ Accepted: March 19, 2019 \\
\hline
\end{tabular}

\title{
HISTOPATHOLOGICAL CHANGES OF THE UMBILICAL CORD IN COMPLICATED PREGNANCIES
}

\author{
Seval KAYA ${ }^{1}$, Yusuf NERGIZ*2, A.Kadir TURGUT ${ }^{3}$ \\ Orcid: 0000-0001-6251-6529; Orcid: 0000-0002-9988-9385; Orcid: 0000-0002-3156-2116 \\ ${ }^{1}$ Dicle University Faculty of Medicine, Department of Histology \& Embryology \\ ${ }^{2}$ Dicle University Faculty of Medicine, Department of Histology \& Embryology \\ ${ }^{3}$ Dicle University Faculty of Medicine, Department of Obstetrics and Gynecology
}

\section{Corresponding author: yusufnergiz21@gmail.com}

\begin{abstract}
Preeclampsia, HELLP syndrome and gestational diabetes are quite common complication in pregnancy. In this study, it is aimed to compare the thickness of basal lamina and vascular structure of umbilical cord. By comparing preeclampsia, HELLP syndrome, gestational diabetes and normal pregnant women. In the study, samples were taken from postpartium umbilical cords of normal pregnant women, preeclampsia, gestational diabetes and pregnant women diagnosed with HELLP syndrome. Umblical cord samples taken during maternity, followed by routine paraffin through fixing $10 \%$ neutral formalin. In this performed as totally sixty facts through taking fifteen umbilical cords from each of four groups, Hematoxyline-eosin, Masson trichrom, periodic acid Schiff, and toluidine blue stain were applied on to the serial histological sections obtained from paraffin blocks. The obtained slides were evaluated with Zeiss Imager A 2 Microscope by taking micrographs. Morphometric measurements were statistically analyzed with SPSS software. In cases of gestational diabetes due to increased collagen production, thickening and excessive narrowing of the lumen and differentiation of Wharton jelly were observe in the umbilical artery. Differentiations are observed in the vacuolization of smooth muscle cells and muscle fibers that make up the media while camber and damage are observed in endothelial. The most significant structural changes of preeclamptic placentas are obtained as the thickening and the endothelial injury. In the umbilical cord artery medial layer, due to the growth of collagen fiber. In HELLP cases due to the increase in media diffuse edema between muscle fibers and in collagen, the thickening of umbilical artery wall and the narrowing of luminal are seen as extremely significant. Another striking symptom with HELLP cases is the observing of intramuscular hemorrhages in the umbilical artery wall as an unattained case in preeclampsia and gestational diabetes. In most of the cases, differentiation in Wharton jelly, metaplastic changes in the amniotic epithelium and thickening of the basal lamina are observed.
\end{abstract}

Key words: Umbilical cord, Preeclampsia, Gestational diabetes, HELLP syndrome 


\section{Introduction}

The umbilical cord plays an important role in interactions between mother and fetus during pregnancy. The folded umbilical cord that connects the fetus to the placenta holds the placenta in centric or eccentric positions, its length being approximately $55 \mathrm{~cm}$ in length.

The two umbilical arteries and a vein are located within the Wharton jelly [1].

Gestational diabetes, HELLP syndrome and preeclampsia are very common complications during pregnancy.

Gestastional Diabetes (GD) is defined as the deterioration of glucose tolerance that occurs or is detected in pregnancy. It is mostly the most common metabolic disorder [2]

Preclampsia, vasospasm and secondary organ perfusion decrease in pregnancy is a disease belonging to [3].

HELLP syndrome is generally considered a severe form of preeclampsia. HELLP syndrome is associated with high maternal and perinatal morbidity and mortality, characterized by hemolysis, elevated liver enzymes and decreased platelet count [4-5].

The aim of this study was to examine and compare the morphological changes in the umbilical cord, such as vascular structures and basal lamina thickness in patients with gestational diabetes, preeclampsia and syndrome.

\section{Material and Methods}

\subsection{Tissue follow up for histopathological examination}

The study was started after the approval of Dicle University Medical Faculty Non- interventional Clinical Research Ethics Committee. This study was performed on the umbilical cord obtained from 15 normotensive, 15 preclampsia, 15 gestational diabetes (GD) and 15 HELLP syndrome cases. Tissue of the umbilical cord $1 \mathrm{~cm}$ in size were taken by the placenta. Tissue samples were fixed in $10 \%$ buffered neutral formalin. Routine histological tissue was followed by paraffin embedded.

5 micrometer thick sections were taken from each paraffin block with the help of the fully automatic rotary microtome (Leica RM 2265, Germany). Hematoxylin-Eosin (H\&E), Masson trichrome and Periodic Acide Schiff (PAS) were applied to the paraffin sections. The preparations were then evaluated by Zeiss Imager A2 light microscope and photomicrographs were taken.

\subsection{Morphometric Measurements}

The cross-sectional area, umblical artery lumen, vein lumen and tunica media thickness were measured by Zeiss axio imager 2 microscope using the Zen 2012 Sp2 (blue edition) program.

Furthermore, macroscopically, each sample was measured with umbilical cord total circumference length and total diameter planimeter.

In each section, the mean of the maximum and minimum diameter values for the measurement of the artery and vein lumen were taken into account. In the measurement of thickness of the tunica medial layer, 1 artery and 1 vein were selected separately for each sample. Five different regions were measured in the media layer and the mean values obtained were measured as the mean thickness of 
tunica media layer. For all samples, total umbilical cord total circumference length, umbilical cord total diameter as well as both artery and vein tunica media layer thickness and lumen diameter averages were obtained.

\subsection{Statistical Analysis}

One-way analysis of variance (ANOVA) test was used to compare the averages of the umbilical cord total measurements, arterial and vein parameters, and in the case of statistical significance, multiple comparisons Dunnett and Tukey HSD multiple comparison tests were used. A $95 \%$ confidence interval was applied in all tests and $\mathrm{p}<0.05$ was considered statistically significant.

\section{Results}

\subsection{Umbilical cord histopathological results}

\subsubsection{Histopathological results of the control group umbilical cord}

Normal histological structure was observed in the umbilical cord sections of the control group. The outermost single-row cubic amniotic epithelium and the Wharton jelly under it observed 2 arteries and 1 vein (Figure 1).

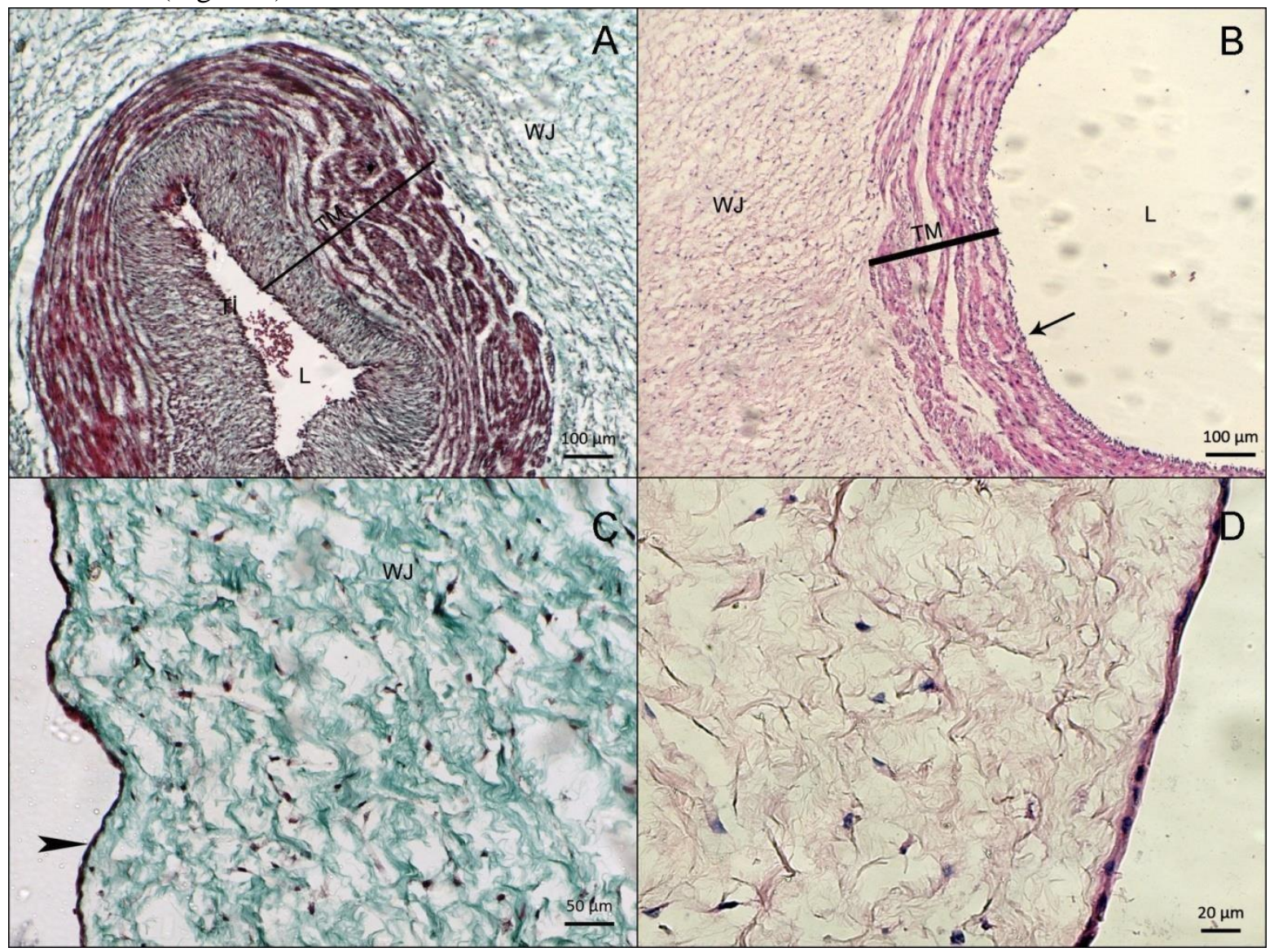

Figure 1. Normotensive section of the umbilical cord sections. a) View of the umbilical artery (Masson trichrome, Bar: $100 \mu \mathrm{m}$ ). b) Umbilical vein appearance (H\&E, Bar: $100 \mu \mathrm{m}$ ). c) Amnion epithelium surrounding the umbilical cord and Wharton gelly. (Masson trichrome, Bar: $50 \mu \mathrm{m}$ ). d) Single-row cubic amnion epithelium in the umbilical cord. (H\&E, Bar: $20 \mu \mathrm{m}$ ). L: Lumen, TIA: Tunica intima, TM: Tunica media, WJ: Wharton gelly, Arrow: Vascular endothelium, Arrow head: Amniotic epithelium 


\subsubsection{Histopathological results of the gestational diabetes group umbilical cord}

Excessive thickening and collapse of the lumen were observed in the umbilical artery wall due to increased collagen (fig. 2a).At tunica media were observed vacuolization and disruption of muscle fibers, while the endothelium showed bulging into lumen and damage (figure-2b). Normally, the circumference of the umbilical vein was observed in the smooth muscle cell line (Figure-2c). Another structural change in the umbilical cord sections of the GD group was metaplasia in the amniotic epithelium (Figure 2d).

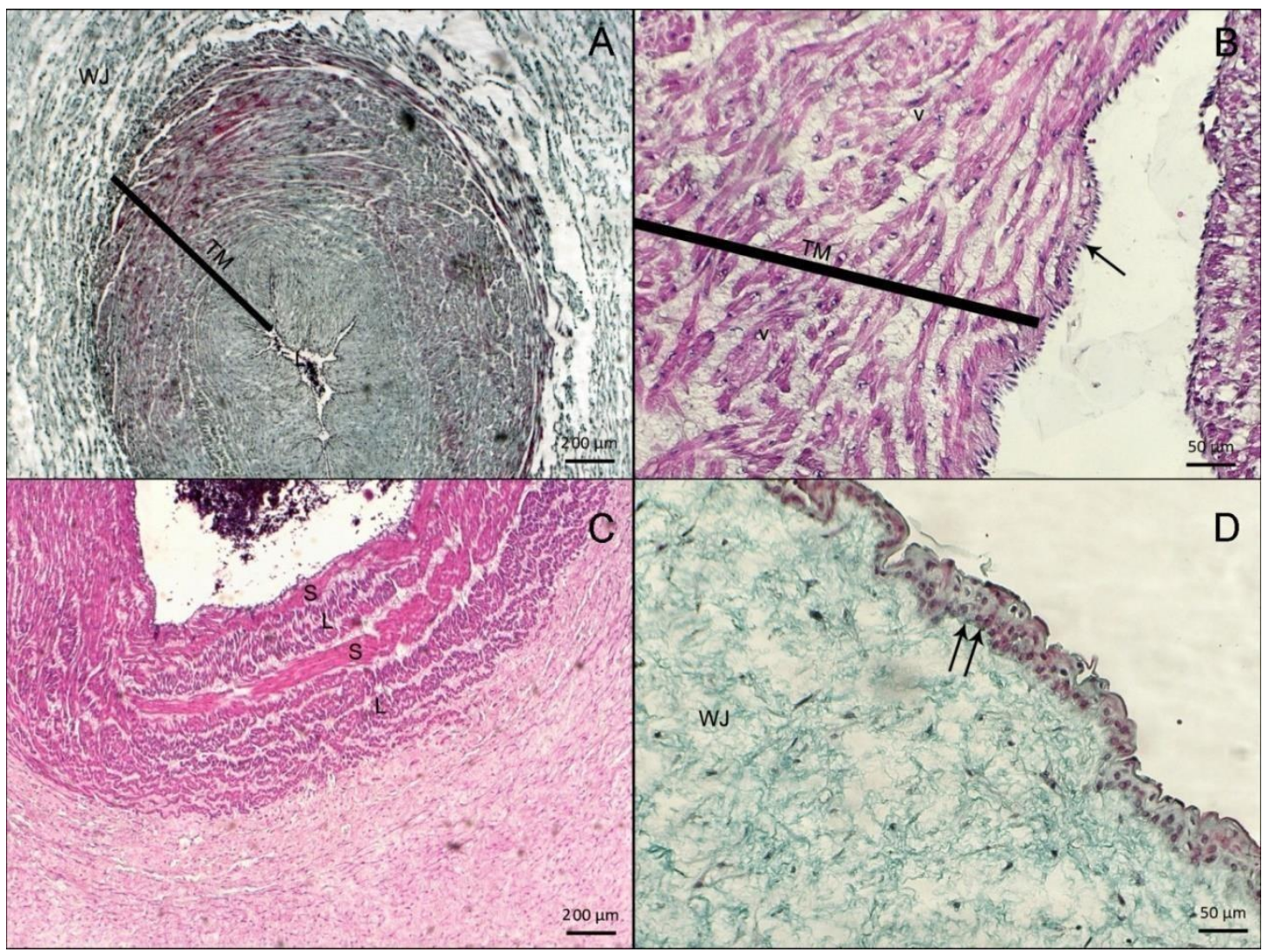

Figure 2. Umbilical cord sections of gestational diabetes group. a: Umbilical cord excessive thickening of the umbilical artery wall (Masson trichrome, Bar: $20 \mu \mathrm{m}$ ). b: Columnar shape in endothelial cell nuclei of umbilical vein, vacuolization and dissociation in tunica medial muscle cells (H-E, Bar: $50 \mu \mathrm{m}$ ). c: Disorganization status in umbilical vein muscle array. (H\&E, Bar: $200 \mu \mathrm{m}$ ). d: Metaplasia in the umbilical cord amnion epithelium (Masson trichrome, Bar: $50 \mu \mathrm{m}$ ). L: Lumen, TM: Tunica media, WJ: Wharton gelly, Arrow: Vascular endothelium, V: vacuolization, S: Circular muscle alignment, Double arrow: Metaplasia, WJ: Wharton gelly.

\subsubsection{Histopathological results of the umbilical cord in the preeclampsia group}

The most significant changes in preeclamptic pregnancies, endothelial injury, and asymmetric thickening due to collagen fiber increase in the media layer of the umbilical artery (Figure 3A).

In some umblical cord sections, umbilical artery media layer showed a snake-like appearance in smooth muscle cell nuclei due to edema, dissociation and contraction (Figure 3B). In the endothelial basal lamina, fragmantation, swelling and undulant laminar changes were observed in all 
umbilical cord veins (Figure 3C). A significant thickening was observed on the amniotic basal lamina (Figure-3D).

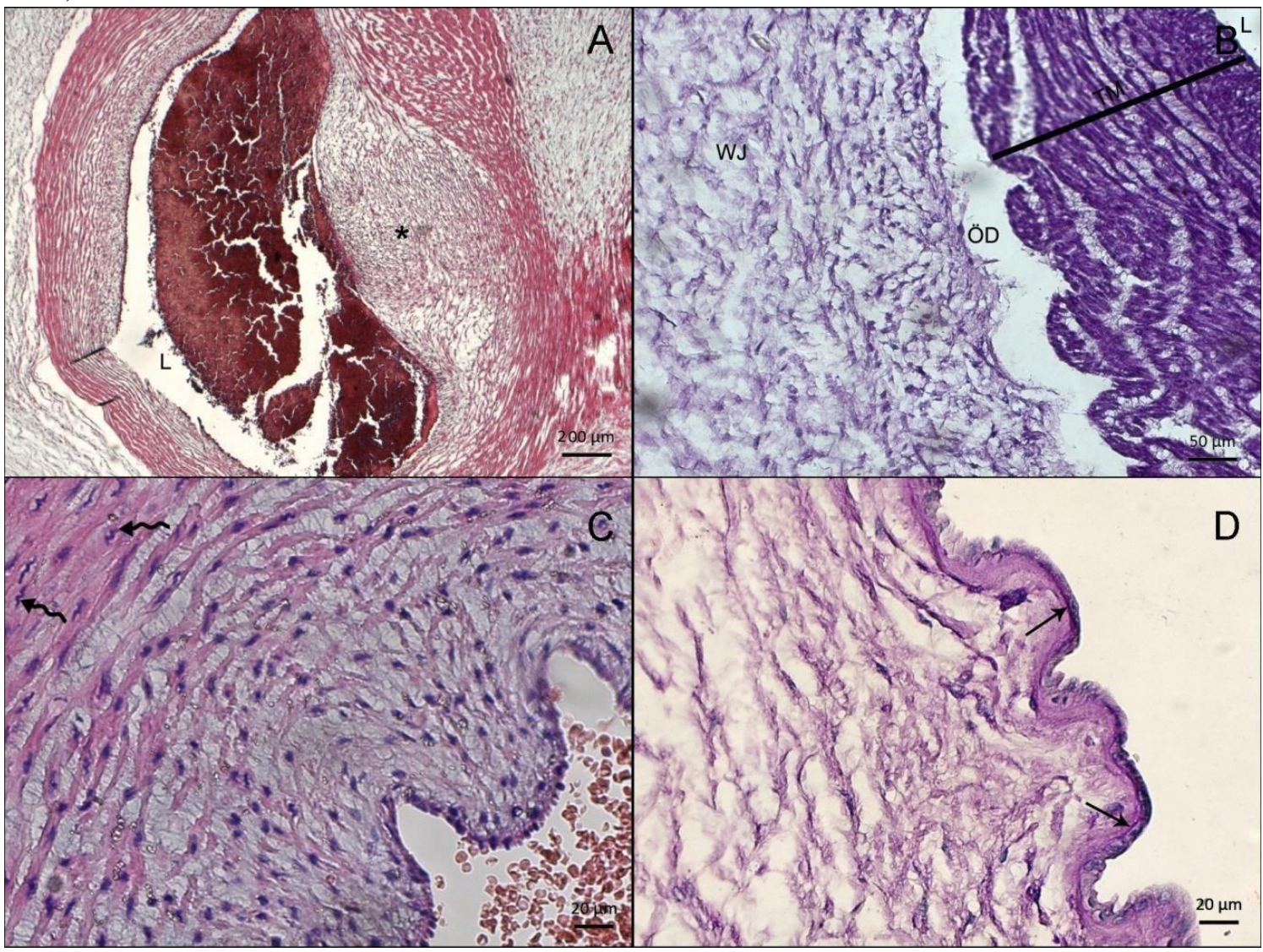

Figure 3. Preeclamptic umbilical cord sections. A: Asymmetric thickening of umbilical artery wall, (Masson trichrome, Bar: $200 \mu \mathrm{m}$ ). B: Muscular disorganization and perivascular edema in the umbilical artery wall, (PAS, Bar: $50 \mu \mathrm{m}$ ). C: Destruction of the umbilical artery endothelium and a snake-like in the muscle cell nuclei, (H\&E, Bar: $20 \mu \mathrm{m})$. D: Thickening of amniotic basal lamina, (PAS, Bar: $20 \mu \mathrm{m}$ ). Asterix: Asymetric thickening, TM: Tunica media, L: Lumen, ÖD: Perivascular edema, Curved arrow: Muscle cell nuclei ,Thick arrow: Amniotic basal lamina.

\subsubsection{Histopathological results of HELLP group umbilical cord.}

Due to diffuse edema and collagen fiber increase in muscle fibers, excessive thickening and luminal narrowing in the umbilical artery wall was very prominent (Figure 4A). In most of the cases, Wharton gelly dehiscence, metaplastic changes in amniotic epithelium and obvious thickening of the basal lamina were detected (Figure 4B). Another striking finding was intramuscular and perivascular hemorrhage in the umbilical artery wall, which was not seen in preeclampsia and GD groups (Figure4C). While endothelial nuclei of the umbilical vessels were prismatic and bulging towards the lumen, in all cases basal lamina was seen to fragment, swelling and ondulations (Figure 4D). 


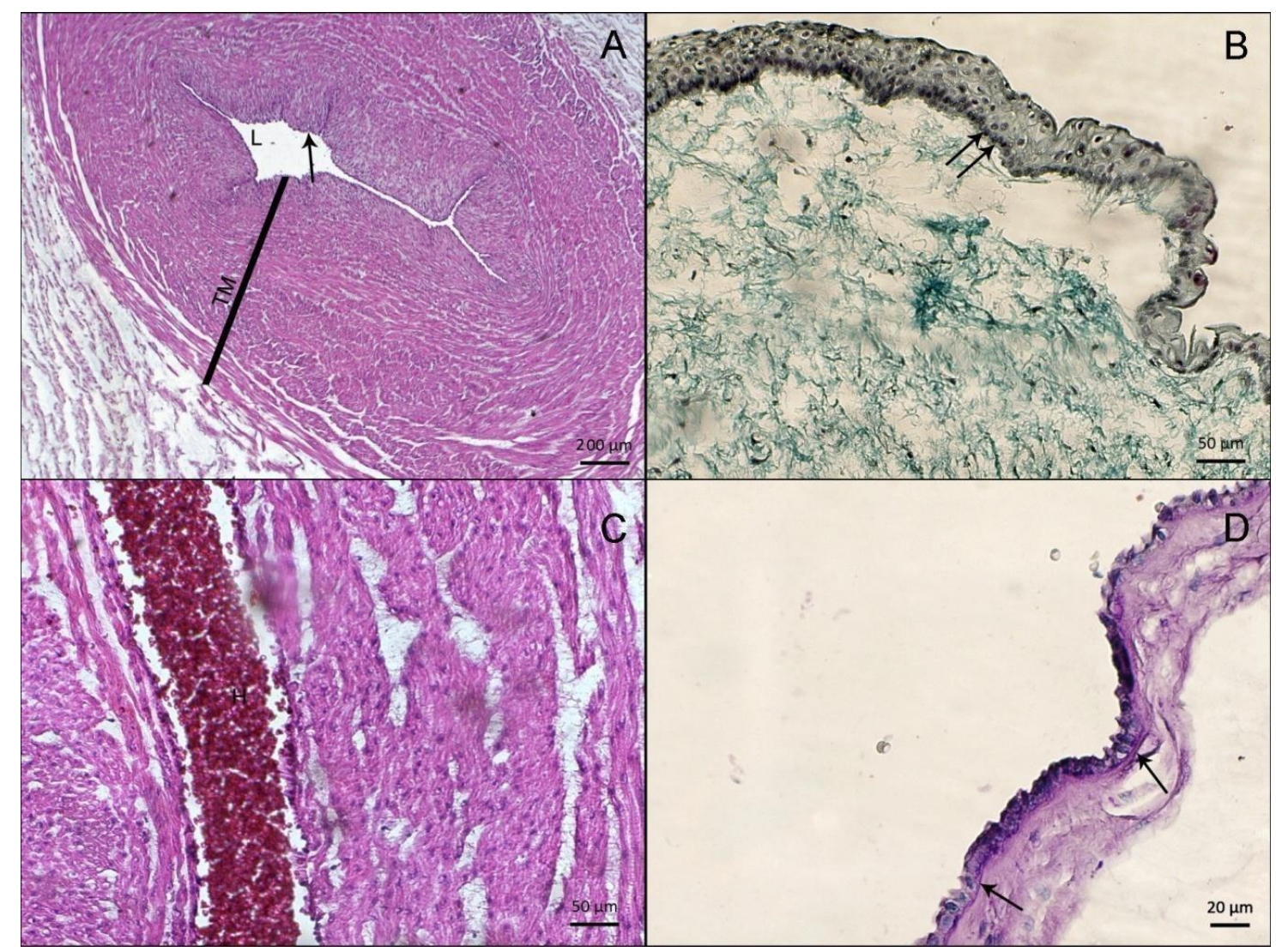

Figure 4. HELLP group umbilical cord sections. A:Advanced thickening of the umbilical artery wall (H\&E, Bar: $200 \mu \mathrm{m}$ ), B:metaplasia in amniotic epithelium (Masson trichrome, Bar:50 $\mu \mathrm{m}$ ), C: Hemorrhage in the umbilical artery tunica media (H-E, Bar: $50 \mu \mathrm{m}$ ), D: Thickening of amniotic epithelium basal lamina (PAS, Bar: $20 \mu \mathrm{m}$ ). L: Lumen, Arrow: Endothelium, TM: Tunica media, H: Hemorrhage, Thick arrow: Amniotic basal lamina.

\subsection{Umbilical cord statistical analysis}

The measurement data of the umbilical vessels are shown in table-1 and the significance status is shown in Table 2. As a result of the measurements, it was observed that there was narrowing of umbilical artery and artery lumen diameter in all three groups according to the control group (Figure 1). A significant thickening of the HELLP, GD and preeclampsia groups was observed in the umbilical artery media (Figure 6).

In the evaluation of umbilical cord vein lumen diameter, it was concluded that only the GD group had dilatation and this measurement was significant (Figure-7). There was a significant thickening $(\mathrm{p}=0.000)$ in the GD group compared to the control group but the HELLP and preeclampsia groups were similar to the control group (Figure 8).

An increase in the perimeter length was found in the GD group compared to the control in the total circumference measurement of the umbilical cord (Figure 9).

There was a significant increase in the umbilical cord diameter in the GD group compared to the control group (Figure 10). 
International J. of Health Services Research and Policy (2019) 4(1): 43-54

Table 1: Morphological measurement data of umbilical cord diameter, circumference and umbilical vein.

\begin{tabular}{|c|c|c|c|c|c|c|}
\hline & Groups & Mean & Standard deviation & $\begin{array}{c}\text { Standard } \\
\text { error }\end{array}$ & Minimum & Maximum \\
\hline \multirow{4}{*}{$\begin{array}{c}\text { Artery lumen } \\
\text { diameter mean. }(\mu \mathrm{m})\end{array}$} & Control & 668,5429 & 41,60216 & 15,72414 & 604,20 & 722,60 \\
\hline & Hellp & 329,8857 & 64,54449 & 24,39552 & 243,20 & 418,60 \\
\hline & Preeclampsia & 292,8286 & 71,41017 & 26,99051 & 197,80 & 380,90 \\
\hline & GD & 325,1000 & 56,82693 & 21,47856 & 227,50 & 393,50 \\
\hline \multirow{4}{*}{$\begin{array}{c}\text { Artery media } \\
\text { thickness mean. } \\
\qquad(\mu \mathrm{m})\end{array}$} & Control & 330,4571 & 35,28290 & 13,33568 & 277,90 & 374,80 \\
\hline & Hellp & 476,4571 & 35,19990 & 13,30431 & 434,60 & 518,70 \\
\hline & Preeclampsia & 472,8857 & 44,10493 & 16,67010 & 412,00 & 529,40 \\
\hline & GD & 734,7286 & 72,15060 & 27,27036 & 627,30 & 853,50 \\
\hline \multirow{4}{*}{$\begin{array}{l}\text { Vein lumen } \\
\text { diameter mean. } \\
(\mu \mathrm{m})\end{array}$} & Control & 1030,0429 & 118,76648 & 44,88951 & 884,00 & 1239,50 \\
\hline & Hellp & 995,5714 & 282,84704 & 106,90613 & 630,20 & 1306,50 \\
\hline & Preeclampsia & 814,4000 & 433,45071 & 163,82897 & 150,60 & 1583,00 \\
\hline & GD & 1582,6571 & 247,92722 & 93,70768 & 1156,50 & 1882,00 \\
\hline \multirow{4}{*}{$\begin{array}{c}\text { Vein media } \\
\text { thickness mean. } \\
(\mu \mathrm{m})\end{array}$} & Control & 363,5757 & 62,32031 & 23,55486 & 307,80 & 482,92 \\
\hline & Hellp & 359,1114 & 113,46184 & 42,88455 & 208,54 & 479,70 \\
\hline & Preeclampsia & 299,7800 & 76,61616 & 28,95819 & 210,12 & 412,16 \\
\hline & GD & 610,8200 & 77,83889 & 29,42033 & 500,62 & 742,38 \\
\hline \multirow{4}{*}{$\begin{array}{c}\text { Total circumference } \\
\text { length. }(\mathrm{cm})\end{array}$} & Control & 3,0571 & 44293 & 16741 & 2,50 & 3,90 \\
\hline & Hellp & 2,6571 &, 17182 & ,06494 & 2,40 & 2,90 \\
\hline & Preeclampsia & 2,8000 & ,48305 &, 18257 & 2,30 & 3,80 \\
\hline & GD & 4,0943 & ,12998 & ,04913 & 3,90 & 4,30 \\
\hline \multirow{4}{*}{$\begin{array}{l}\text { Total diameter } \\
\text { length. }(\mathrm{mm})\end{array}$} & Control & 73,0000 & 6,02771 & 2,27826 & 67,00 & 85,00 \\
\hline & Hellp & 67,2857 & 9,01322 & 3,40668 & 57,00 & 82,00 \\
\hline & Preeclampsia & 78,2857 & 11,49948 & 4,34640 & 62,00 & 95,00 \\
\hline & GD & 110,2857 & 3,03942 & 1,14879 & 107,00 & 116,00 \\
\hline
\end{tabular}

Table 2. Multicenter multiple comparison chart of umbilical cord diameter, circumference and umbilical vein.

\begin{tabular}{|c|c|c|c|}
\hline \multirow{4}{*}{$\begin{array}{c}\text { Artery Lumen } \\
\text { F=61,713 } \\
\mathrm{p}=0,000\end{array}$} & Intergroup pairwise comparisons & $\mathrm{P}$ \\
\cline { 2 - 4 } & Control & Hellp & 0,000 \\
\cline { 2 - 4 } & Control & Preeclampsia & 0,000 \\
\cline { 2 - 4 } & Hellp & GD & 0,000 \\
\cline { 2 - 4 } & Hellp & GD & Ns \\
\hline $\begin{array}{c}\text { Artery Media } \\
\text { F=82,416 } \\
\text { p=0,000 }\end{array}$ & Preeclampsia & GD & Ns \\
\cline { 2 - 4 } & Control & Hellp & 0,000 \\
\cline { 2 - 4 } & Control & Preeclampsia & 0,000 \\
\hline
\end{tabular}


International J. of Health Services Research and Policy (2019) 4(1): 43-54

\begin{tabular}{|c|c|c|c|}
\hline & Control & GD & 0,000 \\
\hline & HELL & Preeclampsia & Ns \\
\hline & HELL & GD & 0,000 \\
\hline & Preeclampsia & GD & 0,000 \\
\hline \multirow{6}{*}{$\begin{array}{c}\text { Vein Lumen } \\
F=8,973 \\
p=0,000\end{array}$} & Control & HELL & $\mathrm{Ns}$ \\
\hline & Control & Preeclampsia & Ns \\
\hline & Control & GD & 0,005 \\
\hline & HELL & Preeclampsia & $\mathrm{Ns}$ \\
\hline & HELL & GD & 0,005 \\
\hline & Preeclampsia & GD & 0,000 \\
\hline \multirow{6}{*}{$\begin{array}{c}\text { Vein Media } \\
F=18,614 \\
p=0,000\end{array}$} & Control & HELL & Ns \\
\hline & Control & Preeclampsia & Ns \\
\hline & Control & GDM & 0,000 \\
\hline & HELL & Preeclampsia & Ns \\
\hline & HELL & GD & 0,000 \\
\hline & Preeclampsia & GD & 0,000 \\
\hline \multirow{6}{*}{$\begin{array}{c}\text { Total } \\
\text { circumferenc } \\
\mathrm{e} \\
\mathrm{F}=24,8 \\
20 \\
\mathrm{p}=0,000\end{array}$} & Control & HELL & Ns \\
\hline & Control & Preeclampsia & Ns \\
\hline & Control & GD & 0,000 \\
\hline & HELL & Preeclampsia & Ns \\
\hline & HELL & GD & 0,000 \\
\hline & Preeclampsia & GD & 0,000 \\
\hline \multirow{6}{*}{$\begin{array}{c}\text { Total } \\
\text { diameter } \\
\mathrm{F}=40,036 \\
\mathrm{p}=0,000\end{array}$} & Control & HELL & Ns \\
\hline & Control & Preeclampsia & Ns \\
\hline & Control & GD & 0,000 \\
\hline & $\begin{array}{c}\text { HELL } \\
P \\
\end{array}$ & Preeclampsia & Ns \\
\hline & HELL & GD & 0,000 \\
\hline & Preeclampsia & GD & 0,000 \\
\hline
\end{tabular}




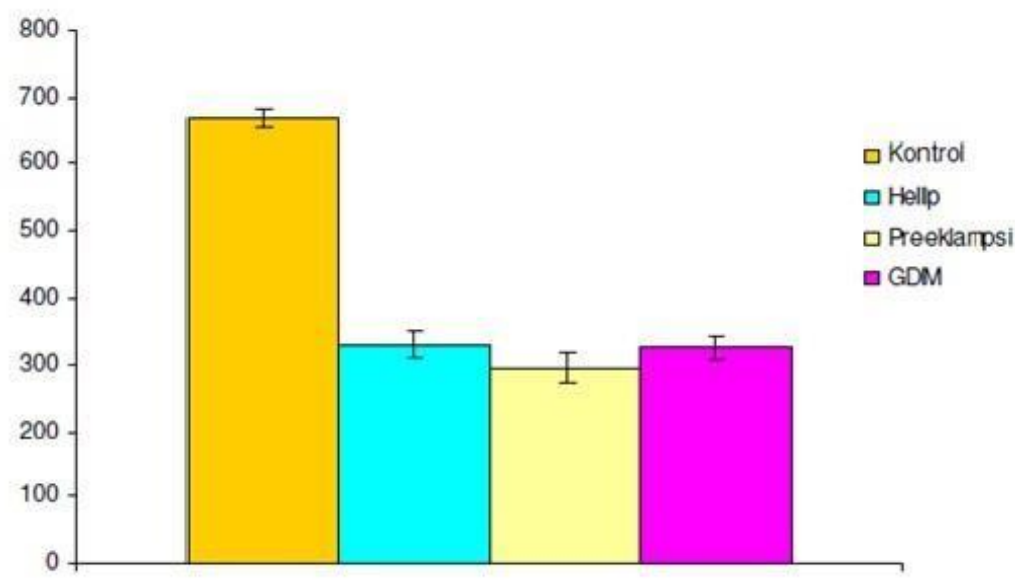

Figure 5: Mean diameter of umbilical artery lumen

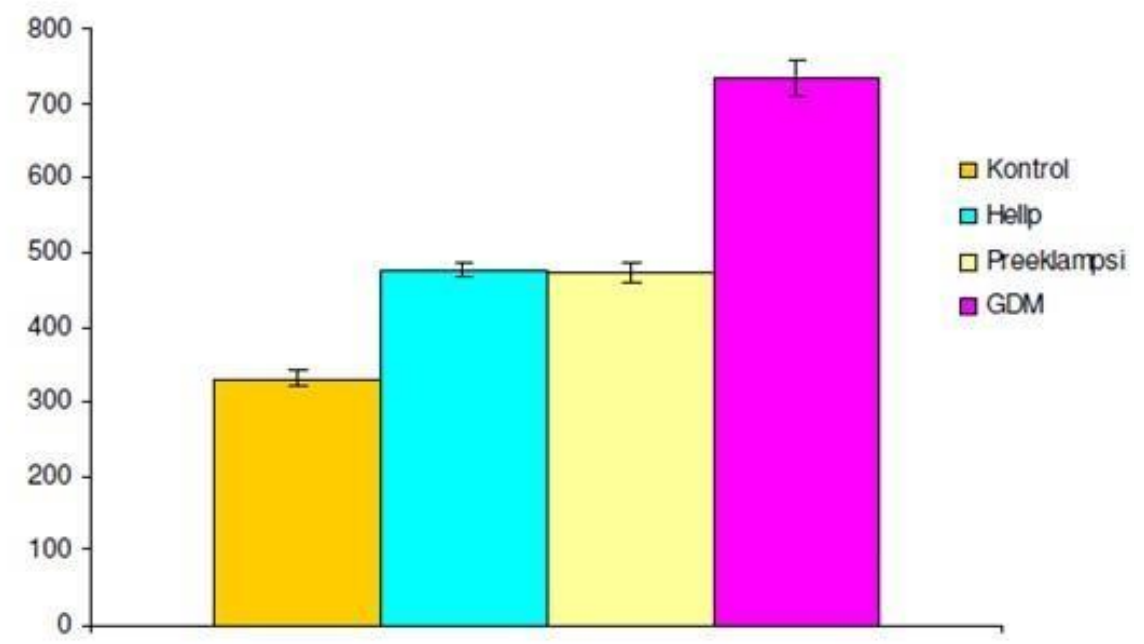

Figure 6. Mean thickness of the umbilical artery tunica media layer

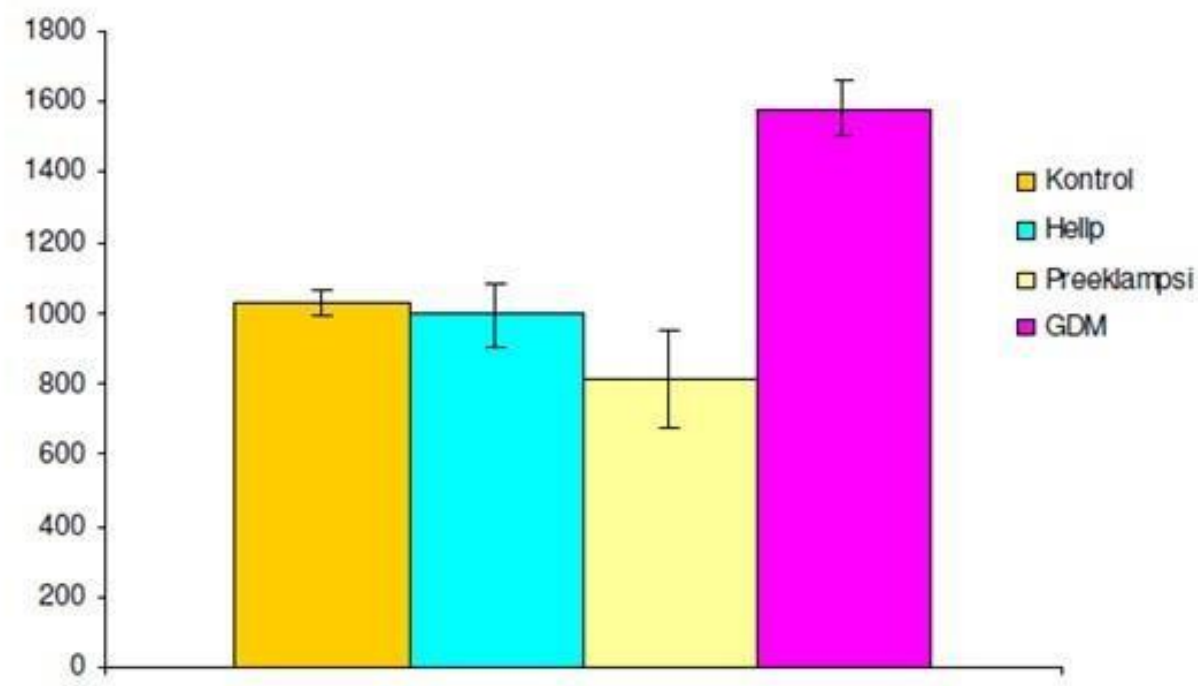

Figure 7. Mean diameter of umbilical vein lumen 


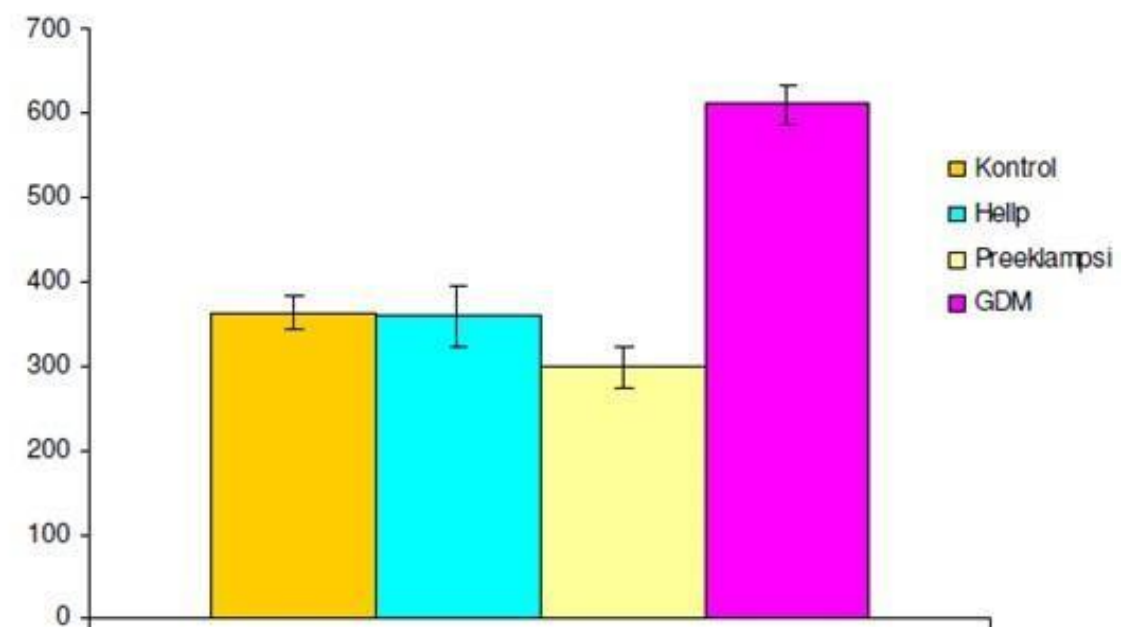

Figure 8. Mean thickness of umbilical vein tunica media layer

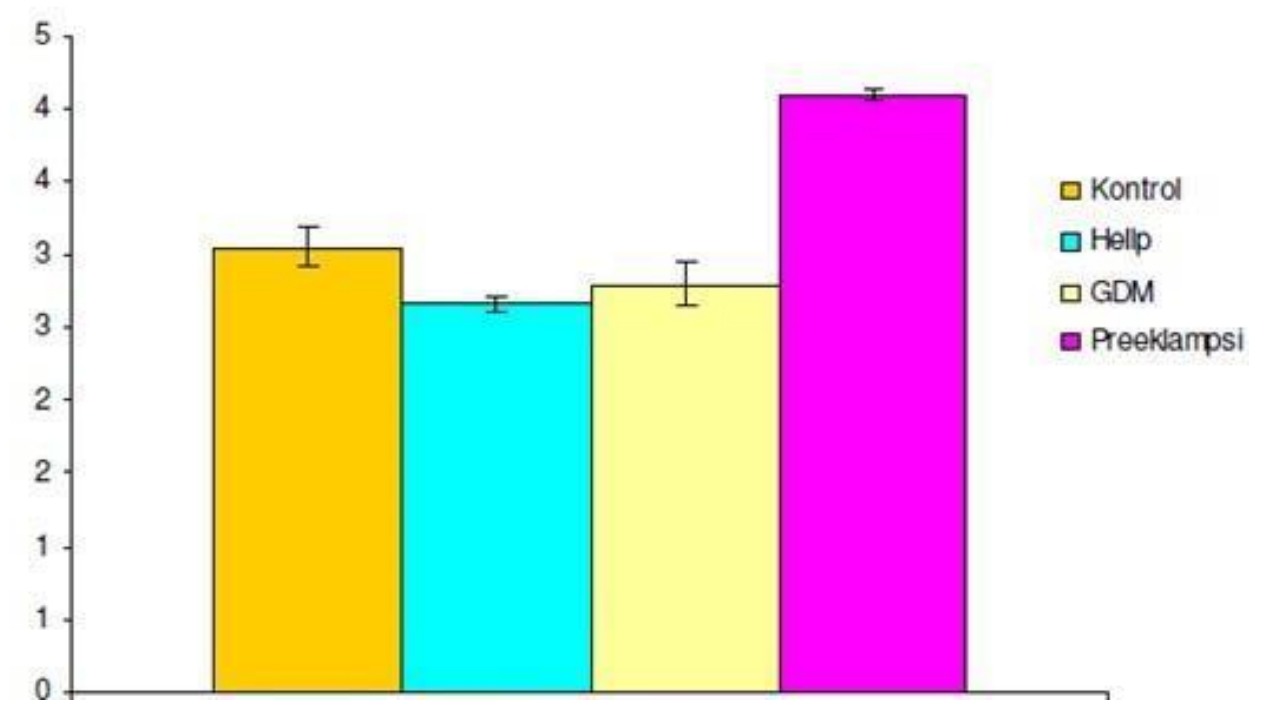

Figure 9. Total circumference of umbilical cord according to the groups

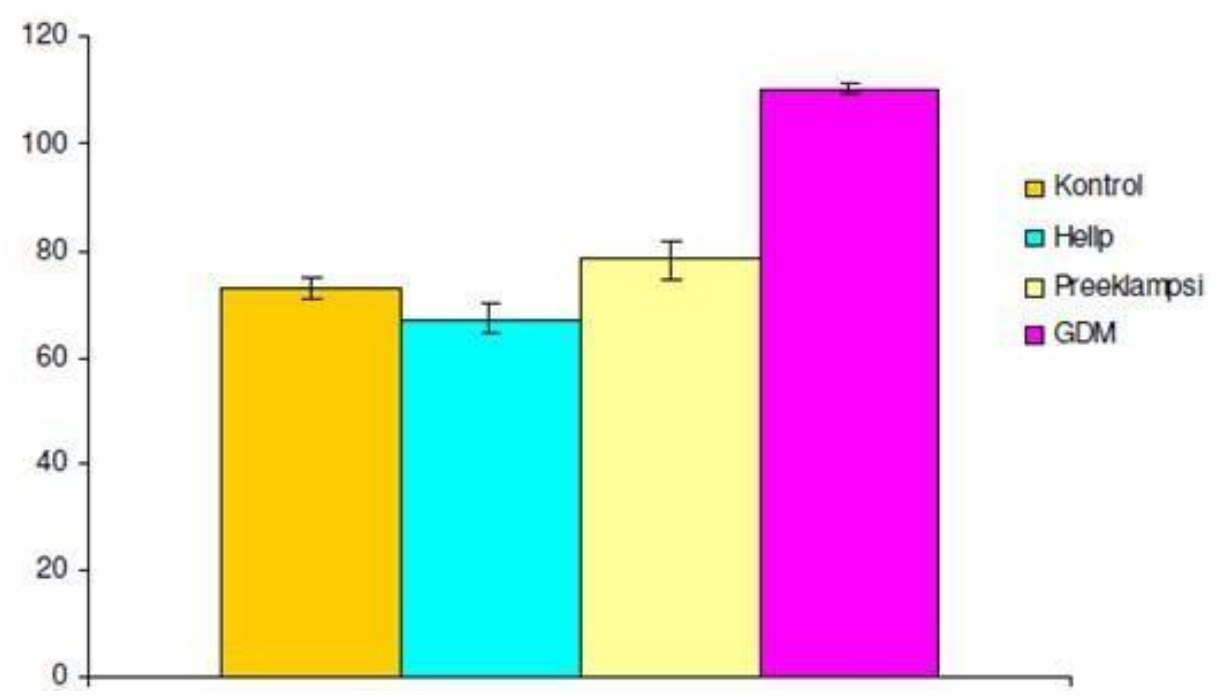

Figure 10. Total diameter of the umbilical cord according to the groups 


\section{Discussion}

In this study, histopathological and morphometric changes in the umbilical cord of patients with gestational diabetes, preeclampsia and HELLP syndrome were examined.

In our study, when we compared the control group, we found that Wharton gelly was more in the GD group and it had many samples. This is in line with the findings of Weissman et al. [6]. Although 2 arteries were found in all the umbilical cord groups (\% 100) and control group (\% 94) in our study groups; 1 patient in the control group and 1 artery in 2 arteries (6\%). Similar phenomena were recorded in Nadkarni as 4\%. Excess umbilical vein is very rare [7-8].

Excess vein structure is generally reported as a vein in publications. Excess vein is the right vein structure that does not undergo atrophy. This structure is the remnant of vitelline veins when the excess vein is in the arterial structure [9-10]. In our case, more veins were more rarely seen in the arterial structure.

Stoker et al. [11] noted that preeclamptic arteries were $15 \%$ thicker than normal pregnancies, but Junek [12] reported this rate as $20 \%$. Our study found this rate to be $50 \%$. This thickness is the result of both the tunica intima and the expansion of the tunica media.

Weissman and Jakobi [6] emphasized that the umbilical cord was thicker in diameter due to the increase in Wharton gelly in GD cases in comparison with the umbilical cord in cases with gestational diabetes. In our study, we found similar results in both GD and HELLP cases

The thickening of the artery intima is due to the accumulation of smooth muscle cells, collagen increase and glycosaminoglycans in the vessel wall. These findings are correlated by the study of Bertrand [13].

It is known that the mother and placenta vascular system affect the intrauterine development of fetus. Preeclampsia is an important pathological syndrome related to pregnancy and affects both the fetus and the mother's vascular system [14].

In a pressure increase in the lumen of the umbilical arteries, the arterial wall is stretched, an increase in tactical structures, and consequently a little thickening in the artery wall compensates itself [14].

In our study, we found similar findings in umbilical arteries. On the other hand, the compensatory state of the umbilical vein is limited in the pressure increase, so that lumina are dilated and the wall was thinner [15].

In our study, although almost all sections of the umbilical cord obtained from cases with preeclampsia, GD and HELLP syndrome had increased endothelial damage and collagen fiber increase in umbilical artery media layer, intramuscular hemorrhage in the media layer of umbilical artery was considered as an interesting finding in patients with HELLP syndrome (Figure-4).

As known, amniotic epithelium surrounding the umbilical cord was simple cubic layer in normal pregnancies, while metaplasia and basal laminar changes (rupture, swelling, ondulation) were observed in GD and preeclamptic cases. However, we would like to emphasize the advanced metaplasia and basal lamina thickening in the amniotic epithelium of the umbilical cord of our cases with HELLP.

Inan et al. [16] emphasized the decrease in wall thickness in umbilical vessels in patients with pre-eclampsia with doppler. These morphological changes were not found to be due to irregularity of blood flow or decreased blood flow. In our study, the vascular wall thickness of the preeclampsia 
umbilical cord was found to be considerably thicker than normal. These results are in contrast to the work of Inan and his friends.

In our study, arterial wall thickness was found more striking than normal in gestational diabetes and HELLP cases. We believe that intense collagen fiber increase observed in umbilical artery wall of our cases with gestational diabetes, preeclamptic and HELLP syndrome will decrease the umbilical blood flow by decreasing the lumina and will have a negative effect on the development of fetus.

\section{Acknowledgment}

This study was supported by Dicle University Research Project no. 14136

\section{References}

[1] Çiftçioğlu MA, Kanadalı S., et al. "Histopathologic changes of umbilical cord in preeclamptic pregnant women", MJAU, 28, 216-219, 1996.

[2] Turok DK, Ratcliffe SD., et al. "Management of gestational diabetes mellitus", $A m$ Fam Physician, 68, 1760-1772, 2003.

[3] Hauth JC, Ewell MG., et al. "Pregnancy outcomes in healthy nulliparas who developed hypertension. Calsium for Preeklampsia Prevention Study Group”, Obstet Gynecol., 95, 24-28, 2000.

[4] Vigil-De-Gracia P., "Pregnancy complicated by preeclampsia-eclampsia with help syndrome”, Int J Gynaecol Obstet., 72, 17-23, 2001.

[5] Martin JN Jr, Blake PG., et al. "Pregnancy complicated by preeclampsia-eclampsia with the syndrome of hemolysis, elevated liver enzymes and low platelet count: How rapid is postpartum recovery?”, Obstet Gynecol., 76, 737-741, 1990.

[6] Weissman A, Jakobi P., "Sonographic measurements of the umbilical cord in pregnancy complicated by gestational diabetes", J Ultrasound Med, 16, 691-694, 1997.

[7] Nadkarni BB., "Congenital anomalies of the human umbilical cord and their clinical significance: alight and electron microscope study”, Indian J Med Res., 57,1018-1057, 1999.

[8] Sepulveda W, Dezerega V, "Fused umblical arteries", J Ultrasound Med., 20, 59-62, 2001.

[9]. Abuhamad A, Sclater AJ., et al., "Umbilical artery Doppler waveform notching: is it a marker for cord and placental abnormalities?" J Ultrasound Med., 21, 857-860, 2002.

[10] Sullivan JB, Charles D., et al., "Gestational diabetes and perinatal mortality", Am J Obstet Gynecol., 116,901-904, 1973.

[11] Stocker TJ, Dehner LP. Pediatric Pathology, JB Lippincott, Philedelphia, 1992.

[12]. Junek T, Baum O., et al., "Preeclampsia associated alterations of the elastin fibre system in umbilical cord vessels", Anat Embryol., 4, 291-303, 2001.

[13] Bertrand C, Duperron L., et al., "Umbilical and placental vessels: Modification of their mechanical properties in preeclampsia”, Am J Obstret Gynecol., 168, 1537-1546, 1993.

[14] Barnwal M, Rathi SK., et al., "Histomorphometry of umbilical cord and its vessels in preeclampsia as compared to normal pregnancies", NJOG., 7, 28-32, 2012.

[15]. Romanowicz L and Sobolewski K., "Extracellular matrix components of the wall of umbilical cord vein and their alterations in preeclampsia", J Perinat Med., 28, 140-146, 2000.

[16] Halim A, Kanayama N., et al., "HELLP syndrome-like biochemical parameters obtained with endothelin-1 injections in rabbits”, Gynecol Obstet Inverst., 35, 193-198, 1993. 